\title{
COEFICIENTES DE CULTURA DA CHICÓRIA (Cichorium endivia L.)
}

\author{
Aquiles Sandanielo \\ Departamento de Solos e Engenharia Rural, Universidade Federal de Mato Grosso, \\ CEP 78060-900, Cuiabá-MT, Fone (0xx65) 615-8602 \\ Dalva Martinelli Cury Lunardi \\ Departamento de Recursos Naturais, Faculdade de Ciências Agronômicas, Universidade Estadual \\ Paulista, CEP 18603-970,Botucatu-SP,E-mail: lunardi@fca.unesp.br
}

\section{RESUMO}

O conhecimento do coeficiente de cultura $(\mathrm{Kc})$ permite a estimativa das necessidades hídricas de uma cultura, sendo fundamental para o manejo da irrigação. Nesta pesquisa, conduzida na área experimental do Departamento de Recursos Naturais da Faculdade de Ciências Agronômicas FCA/UNESP, Campus de Botucatu, utilizou-se, para medida da evapotranspiração da cultura (ETc), 4 evapotranspirômetros de nível freático constante. Desses, 2 foram cobertos com plástico transparente rente ao solo, a fim de se evitar a evaporação. A evapotranspiração de referência (ETo) foi estimada pelo método de Penman-Monteith, sendo o coeficiente de cultura da chicória (Cichorium endivia L.) dado pela relação: $\mathrm{kc}=\mathrm{ETc} / \mathrm{ETo}$, em suas diversas fases de desenvolvimento. Os valores de (Kc) obtidos evidenciaram um comportamento crescente durante todo o período vegetativo, com a influência da cobertura plástica na fase inicial quando a evaporação do solo representa uma fração considerável da evapotranspiração da cultura .

UNITERMOS: evapotranspiração, coeficiente de cultura, Cichorium endivia L.

\section{SANDANIELO, A., LUNARDI, D.M.C. CROP COEFFICIENTS OF ENDIVE (Cichorium endivia L.)}

\section{ABSTRACT}

The crop coefficient $(\mathrm{Kc})$ is very important for irrigation management programs. This research carried out at the experimental area of the Natural Resource Department of the Agricultural Science College - FCA/UNESP has used 4 constant level evapotranspirometers to determine crop evapotranspiration (ETc) and crop coefficient $(\mathrm{Kc})$ of endive. The soil evaporation was obstructed by a transparent plastic cover over 2 of the evapotranspirometers. The reference evapotranspiration was estimated by Penman-Monteith method. The crop coefficient Kc, during all vegetative crop period was obtained by $\mathrm{kc}=\mathrm{ETc} / \mathrm{Eto}$. The $\mathrm{kc}$ values increased from transplanting to harvest showing influence of the plastic cover especially in the initial phase.

KEYWORDS: evapotranspiration, crop coefficient, Cichorium endivia $\mathbf{L}$. 


\section{INTRODUÇÃO}

A chicória (Cichorium endivia L.) é uma espécie da família Asteraceae, constituindo o grupo de hortaliças folhosas mais populares no Brasil, e já utilizada como alimento pelos antigos egípcios, gregos e romanos (Camargo,1981). Dentro da espécie botânica, são plantadas comercialmente a chicória crespa ou endívia, e a chicória lisa ou escarola, sendo as lisas de maior valor de mercado (Filgueira, 2000).

As asteráceas são muito exigentes em água, desenvolvendo-se e alcançando produção agrícola quando a umidade no solo, em torno de $80 \%$ da água disponível, atinge 0,20 a $0,30 \mathrm{~m}$ de profundidade, região na qual, há maior concentração de todo o sistema radicular da planta (Filgueira, 2000).

$\mathrm{O}$ fornecimento de água em níveis da demanda evapotranspirométrica, ao longo de todo o ciclo da cultura, através da prática da tecnologia da irrigação, possibilitando o ótimo desenvolvimento vegetativo e produção agrícola comercial, vem de encontro à preocupante necessidade de manejar e adequar as disponibilidades naturais e/ou artificiais dos recursos hídricos (Matzenauer, 1992).

A evapotranspiração pode se processar na forma potencial, máxima ou real, dependendo das condições da superfície considerada e da disponibilidade de água no solo (Ometto, 1981).

O termo evapotranspiração de referência (ETo) foi introduzido por Doorenbos \& Pruitt (1977) e definido como a evapotranspiração de uma extensa superfície de grama, de 8 a $15 \mathrm{~cm}$ de altura, em crescimento ativo, cobrindo totalmente a superfície do solo e sem nenhuma restrição hídrica e, por Smith (1991), como a evapotranspiração de uma cultura hipotética, com altura de $0,12 \mathrm{~m}$, albedo igual a 0,23 , em pleno vigor vegetativo e resistência da cobertura ao transporte de vapor d'água igual a $69 \mathrm{~s} \mathrm{~m}^{-1}$.

Jensen (1974) define lisímetros como reservatórios abastecidos com solo, nos quais as culturas desenvolvem-se em condições naturais a fim de que se possa medir a quantidade de água perdida por evaporação e transpiração, fornecendo uma estimativa direta da taxa de evapotranspiração.

Lisímetros ou evapotranspirômetros, de lençol freático constante, percolação e de pesagem, têm sido utilizados na medida da evapotranspiração da cultura (ETc) ou demanda ideal de água (Jensen, 1974). Os de lençol freático constante, devido ao fácil manuseio e a boa precisão na obtenção dos dados, destacamse dentre outros Moura (1992), Cury (1985) e Barbieri (1981).

O coeficiente de cultura $(\mathrm{Kc})$ dado pela razão entre a evapotranspiração da cultura (ETc) e a evapotranspiração de referência (ETo) é função da espécie, do estádio do desenvolvimento e do índice de área foliar, e tem sido determinado para uma grande diversidade de culturas, tais como, couvebrócolo (Fontes, 1996), alface (Bastos, 1994) e batata (Encarnação, 1987).

As estimativas experimentais dos coeficientes de cultura $(\mathrm{Kc})$ permitem o conhecimento das necessidades hídricas de uma cultura, constituindo grande importância no manejo da irrigação. Esta pesquisa teve como objetivo determinar os coeficientes de cultura da chicória (Cichorium endivia L.) cultivar Amazonas Gigante, com e sem cobertura plástica da superfície do solo, nas fases de desenvolvimento da cultura.

\section{MATERIAL E MÉTODOS}

A pesquisa foi conduzida na área experimental do Departamento de Recursos Naturais da Faculdade de Ciências Agronômicas - FCA/UNESP, localizada na Fazenda Experimental Lageado, município de Botucatu - SP. O solo local é caracterizado como Latossolo Roxo Distrófico A Moderado, textura argilosa, e o clima, de acordo com a classificação de Köeppen, definido como Cfa ou temperado chuvoso, úmido e com verões quentes.

A cultura utilizada foi a chicória (Cichorium endivia L.) cultivar Amazonas Gigante, que dentro do grupo lisa (escarola) 
destaca-se pelo seu vigor e tolerância ao frio (Filgueira, 2000).

No experimento foram utilizados 4 evapotranspirômetros com o nível freático constante a $0,30 \mathrm{~m}$ da superfície do solo. A área total plantada foi de $25,0 \times 14,5 \mathrm{~m}$, sendo a bordadura irrigada por aspersão de forma a manter os potenciais de água no solo à $0,10 \mathrm{e}$ $0,20 \mathrm{~m}$ de profundidade, na ordem de 05 a $20 \mathrm{kPa}$.

O transplantio das mudas ocorreu em 31.07.1997, 30 dias após a semeadura, no espaçamento de $0,25 \times 0,25 \mathrm{~m}$, tanto na área de bordadura quanto nas caixas evapotranspirométricas. A adubação e os tratos culturais, de acordo com as exigências da cultura, permitiram o desenvolvimento vegetativo livre de ataques de pragas e doenças.

A evaporação do solo em duas caixas evapotranspirométricas foi eliminada, cobrindose a superfície do solo com plástico transparente de $0,2 \mathrm{~mm}$ de espessura, sendo o transplante realizado em aberturas feitas com um estilete.

A avaliação semanal do desenvolvimento da cultura nos evapotranspirômetros, foi realizada a partir de amostragens de área foliar e de massa seca de plantas da área de bordadura, coletadas aos 07, 14, 21, 28, 35 e 42 dias após o transplante das mudas (Sandanielo, 2000).

O ciclo completo da cultura, mediante ajuste funcional do Índice de Área Foliar (IAF), Taxa Assimilatória Líquida (TAL) e Taxa de Crescimento da Cultura (TCC), foi dividido em estádios, como segue:

Estádio I ou inicial - compreende os primeiros 14 dias após o transplante, sendo caracterizado por um crescimento lento ou de estabelecimento da cultura.

Estádio II ou intermediário - dos 15 aos 28 dias após o transplante, quando ocorre a consolidação da cultura, com grande multiplicação e expansão foliar.

Estádio III ou final - do $29^{\circ}$ dia até a colheita, 42 dias, caracterizado por baixa eficiência fotossintética e alta taxa de crescimento.

A evapotranspiração diária da cultura (ETc), medida pelos evapotranspirômetros com e sem cobertura plástica era obtida às 8:00
horas.Na estimativa da evapotranspiração de referência (ETo), $\mathrm{mm} /$ dia, pelo método de Penman-Monteith (Smith, 1991), foram utilizados os dados climáticos coletados na Estação Agrometeorológica localizada na mesma área experimental.

Os coeficientes de cultura $(\mathrm{Kc})$ foram obtidos pela relação entre a evapotranspiração da cultura (ETc) e a evapotranspiração de referência (ETo), ao longo de todo o ciclo da cultura, nos evapotranspirômetros com e sem cobertura plástica da superfície do solo.

\section{RESULTADOS E DISCUSSÃO}

O cultivo da chicória (cichorium endiva 1.) cv. Amazonas Gigante em evapotranspirômetros, com e sem cobertura plásticas no solo, teve um consumo total de 184,9 e 191,7 litros respectivamente sendo, portanto $4 \%$ maior sem a cobertura plástica. Todavia, isto não se refletiu no peso médio tendo em vista que as plantas dos evapotranspirômetros, com cobertura plástica tiveram $21,3 \%$ a mais de peso.Isto é justificado pelo maior teor de umidade no solo coberto com plástico, desde os primeiros dias do ciclo, possibilitando uma maior eficiência fotossintética das plantas, refletido no ganho de peso.

Os valores de Kc nas diversas fases da cultura evidenciam aumento gradativo com o desenvolvimento da chicória o que, segundo Matzenauer (1985), em cultivo de milho (Zea mays), deve-se à elevação do Índice de Área Foliar (IAF), além do incremento da demanda evaporativa. Fontes (1996) e Bastos (1994), respectivamente, em cultivo de couve-brócolo (Brassica oleracea var. italica) e alface (Lactuca sativa L.), em lisímetros com nível freático constante, alcançaram resultados semelhantes.

A diversidade entre os valores de coeficientes de cultura, no estádio I ou inicio do desenvolvimento vegetativo com e sem cobertura plástica do solo, conforme quadro 1, deve-se à fração considerável que a evaporação representa da evapotranspiração da cultura. Nos 
estádios II e III, 15 dias após o plantio, o aumento do índice de área foliar torna a evaporação do solo insignificante e os valores de kc apresentam maior sensibilidade aos elementos de clima se aproximando nos dois tratamentos.

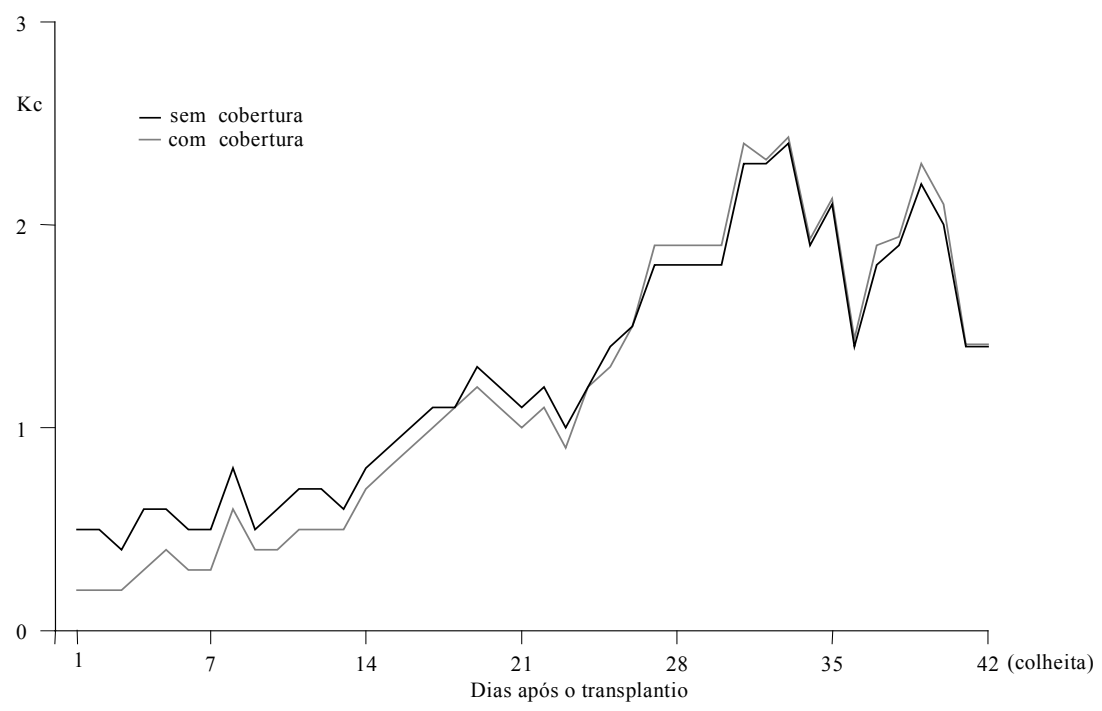

Figura 1: Coeficientes de cultura da chicória (Kc), sem e com cobertura plástica da superfície do solo.

Quadro 1: Coeficientes de cultura da chicória $(\mathrm{Kc})$ nos estádios de desenvolvimento, com e sem cobertura plástica da superfície do solo.
Evapotranspirômetros
Estádio I (x)
Estádio II $(\mathrm{x})$
Estádio III (x)

$\begin{array}{llll}\text { sem cobertura plástica } & 0,4-0,8(0,59)^{1} & 0,9-1,8(1,26)^{2} & 1,4-2,4(1,91)^{2} \\ \text { com cobertura plástica } & 0,2-0,7(0,39)^{1} & 0,8-1,9(1,21)^{2} & 1,4-2,4(1,95)^{2}\end{array}$

$\mathrm{x}$ : valor médio do período

${ }^{1}$ : diferem a nível de $5 \%$ de probabilidade pelo teste $t$ de Student

${ }^{2}:$ não diferem a nível de $5 \%$ de probabilidade pelo teste $\mathrm{t}$ de Student, na coluna

\section{CONCLUSÕES}

Os coeficientes de cultura da chicória apresentaram aumento gradativo do transplante das mudas à colheita, expressando crescente demanda de água com o desenvolvimento vegetativo da cultura.

No inicio do desenvolvimento $80 \%$ da perda de água da cultura foi devido a evaporação do solo.

\section{REFERÊNCIAS BIBLIOGRÁFICAS}

\section{BARBIERI, W. Medidas e estimativas de} consumo hídrico em cana-de-açúcar (Saccharum spp)., 1981. 82 f. Dissertação (Mestrado em Agrometeorologia) - Escola Superior de Agricultura "Luiz de Queiróz", Universidade de São Paulo, Piracicaba, 1981. BASTOS, E.A. Determinação dos coeficientes de cultura da alface (Lactuca sativa L.). 1994. 
101 f. Dissertação (Mestrado em

Agronomia/Irrigação e Drenagem) - Faculdade de Ciências Agronômicas, Universidade Estadual Paulista, Botucatu, 1994.

CAMARGO, L. de. As hortaliças e seu cultivo. Campinas: Fundação Cargill, 1981. $321 \mathrm{p}$.

CURY, D.M. Demanda de água na cultura do repolho (Brassica oleracea var. capitata L.).

1985. 79 f. Tese (Doutorado em

Agronomia/Solos e Nutrição de Plantas) -

Escola Superior de Agricultura "Luiz de

Queiróz”, Universidade de São Paulo,

Piracicaba, 1985.

DOORENBOS, J.; PRUITT, W.O. Las

necessidades de água de los cultivos. Roma :

FAO, 1977. 194 p. (Riego y Drenage, 24)

ENCARNAÇÃO, C.R.F. Exigências hídricas e coeficientes culturais da batata (Solanum tuberosum L.). 1987. 53 f. Tese (Doutorado em Agronomia/Solos e Nutrição de Plantas) -

Escola Superior de Agricultura "Luiz de

Queiróz”, Universidade de São Paulo,

Piracicaba, 1987.

FILGUEIRA, F.A.R. Asteráceas. In: Manual de olericultura. 3. ed. Viçosa: Editora

Universidade Federal de Viçosa, 2000. p. 289295.

FONTES, E.S. Evapotranspiração e coeficiente de cultura da couve-brócolo (Brassica oleracea var. italica) em dois níveis de lençol freático. 1996. 89 f. Dissertação

(Mestrado em Agronomia/Irrigação e

Drenagem) - Faculdade de Ciências

Agronômicas, Universidade Estadual Paulista,

Botucatu, 1996.

JENSEN, M.E. Consumptive use of water and irrigation water requeriment. New York:
American Society of Engineers, Irrigation and Drainage Division, 1974. 227 p.

MATZENAUER, R. Determinação do coeficiente de cultura do milho (Zea mays L.) em duas épocas de semeadura. In:

CONGRESSO BRASILEIRO DE AGROMETEOROLOGIA, 4., 1985, Londrina. Resumos... Campinas: Fundação Cargill, 1985. p. 18-20.

MATZENAUER, R. Evapotranspiração de plantas cultivadas e coeficientes de culturas. In: BERGAMASCHI, H. Agrometeorologia aplicada a irrigação. Porto Alegre: Editora Universidade, Universidade Federal do Rio Grande do Sul, 1992. p. 33-47.

MOURA, M.V.T. Determinação do consumo de água na cultura da cenoura (Daucus carota $L_{\text {.) }}$ através dos métodos lisimétrico e balanço hídrico sob condições de campo. 1992. 84 f. Dissertação (Mestrado em Agronomia/Irrigação e Drenagem) - Escola Superior de Agricultura "Luiz de Queiróz", Universidade de São Paulo, Piracicaba, 1992. OMETTO, J.C. Bioclimatologia vegetal. São Paulo: Agronômica Ceres, 1981. 441 p. SANDANIELO, A. Demanda de água da chicória (Cichorium endivia L.) em evapotranspirômetros, com e sem cobertura plástica do solo. 2000. $73 \mathrm{f}$. Tese (Doutorado em Agronomia/Irrigação e Drenagem) Faculdade de Ciências Agronômicas, Universidade Estadual Paulista, Botucatu, 2000. SMITH, M. Report on the consultation on procedures for revision of FAO guidelines for prediction of crop water requirements. Roma: FAO, 1991. 45 p. 